\title{
Haptic Breakage after Transscleral Fixation of a Single-Piece Acrylic Intraocular Lens
}

\author{
Hiroki Tanaka ${ }^{a, b}$ Kaoru Fujinami ${ }^{a-d}$ Ken Watanabe ${ }^{a, b}$ Toru Noda ${ }^{a, b}$ \\ Kunihiko Akiyama ${ }^{a, b}$ \\ ${ }^{a}$ Department of Ophthalmology, National Hospital Organization, National Tokyo Medical \\ Center, ${ }^{b}$ Laboratory of Visual Physiology, National Institute of Sensory Organs, National

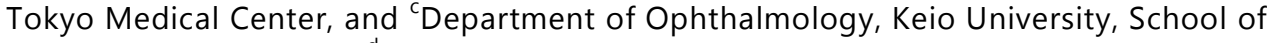 \\ Medicine, Tokyo, Japan; ${ }^{d}$ UCL Institute of Ophthalmology, London, UK
}

\section{Key Words}

Intraocular lens · Acrylic intraocular lens · Intraocular lens damage $\cdot$ Transscleral fixation

\begin{abstract}
Purpose: To report the case of a patient with a damaged haptic of an acrylic intraocular lens (IOL) after transscleral IOL fixation. Methods: This is a retrospective and descriptive case report. Results: A 40-year-old man presented with sudden visual loss in the left eye. He had undergone phacoemulsification/aspiration and IOL implantation 3 years previously and IOL repositioning with transscleral fixation 2 years before the initial visit. His visual acuity was 0.3 in the left eye due to corneal edema caused by a foreign body, i.e., the severed haptic tip of the single-piece acrylic IOL, which was surgically removed. The IOL itself was tilted and therefore explanted. The surface of the tip of the haptic suggested that the monofilament suture thread had exerted continuous force across the haptic. Conclusions: The haptics of acrylic IOLs can be damaged after transscleral fixation.

(C) 2014 S. Karger AG, Basel
\end{abstract}

\section{Introduction}

Foldable intraocular lenses (IOLs) have recently replaced polymethylmethacrylate IOLs for use in transscleral fixation surgery and standard cataract surgery because they can be implanted through a small incision. Favorable outcomes with sutured acrylic IOLs have been reported [1-6]. 
Tanaka et al.: Haptic Breakage after Transscleral Fixation of a Single-Piece Acrylic Intraocular Lens

However, various postoperative complications associated with suturing foldable IOLs have also been discussed, since they are not designed for transscleral suturing [1, 6-11]. We report a case with a damaged haptic of a single-piece acrylic IOL 2 years after transscleral fixation.

\section{Case Report}

A 40-year-old man was referred with sudden visual loss in his left eye (LE) in October 2010. Informed consent was obtained, and the treatment protocol has been approved by the local committee of the National Tokyo Medical Center.

In 2007, he underwent phacoemulsification and IOL implantation for a cataract in the LE. IOL subluxation occurred in 2008, and the patient underwent a repositioning surgery, with suturing of the IOL transsclerally without IOL exchange. The vision improved postoperatively based on the history taken from the patient. Detailed information of these two surgeries performed prior to the initial visit to our institute was unavailable; the underlying pathogenesis of the cataract and IOL subluxation was unknown.

At the initial examination in our clinic, best-corrected visual acuity (BCVA) was 0.3 with correction of $-3.75 /-2.25 \times 180$ in the LE. Slit-lamp examination showed prominent corneal stromal edema from 2 to 7 o'clock (fig. 1a, b). The implanted IOL was seen in the posterior chamber through a hazy cornea. Gonioscopy showed a foreign body at the bottom of the anterior chamber touching the corneal epithelium (fig. 1c). Based on its color and shape, the foreign body was thought to be the distant tip of a haptic of a single-piece acrylic IOL.

The foreign body was removed immediately at the initial visit. Postoperatively, the corneal condition, presumably resulting from the foreign body, recovered gradually within 2 months and the edema resolved; the endothelial cell count was 1,744 cells $/ \mathrm{mm}^{2}$, and the BCVA was 1.0 with correction of $-2.25 /-2.00 \times 180$. During the postoperative comprehensive ophthalmologic examination, the IOL was seen to be slightly tilted and mobile and one of the haptics was damaged; otherwise, no abnormality was seen in the fundus or posterior chamber.

An IOL exchange was performed combined with 25-gauge pars plana 3-port vitrectomy in February 2011. Intraoperatively, the sutured side of the IOL was observed with scleral indentation; the haptic was sutured firmly at the appropriate position (10 o'clock) in the ciliary sulcus. The opposite haptic was severed at the point where it was supposed to have been sutured. There was no fragment of the lens capsule left on the ciliary body. The suture was resected with vitreous scissors, and the IOL was removed through a scleral tunnel. A new acrylic IOL designed for a suturing procedure (YA-65BB, HOYA Corp.) [12] was implanted using the standard transscleral fixation procedure; YA-65BB has the largest diameter of $13 \mathrm{~mm}$ with PMMA haptics which have bulbs on the haptic tips to affix the suture. The BCVA improved to 1.2 with correction of cylinder of $-2.00 \times 135,1$ month later. The tip of the haptic extracted previously was part of the explanted IOL, which was identified as a single-piece acrylic lens (AcrySof SA60AT, Alcon Laboratories). The damaged site of the haptic was directly opposite the point at which the other maintained haptic was sutured but slightly proximal to the optic (fig. 2a). The detailed observation of each fragment revealed that the two parts fit together perfectly with no other parts of the IOL missing. The surfaces of the severed portions were relatively smooth and flat with numerous tiny fissures (fig. 2b). A thin monofilament suture thread was also seen adhering to the proximal aspect of the severed haptic (fig. 2c). The distance between the site of the damage and the point of the suture on the other side was $10.5 \mathrm{~mm}$. 
Tanaka et al.: Haptic Breakage after Transscleral Fixation of a Single-Piece Acrylic Intraocular Lens

\section{Discussion}

Transscleral fixation is a desirable method to implant IOLs in eyes with inadequate capsular support. Along with the trend toward small-incision surgery, foldable IOLs have become a favorable alternative to transscleral fixation [1-6]. Transscleral fixation has also been performed during surgery to reposition dislocated IOLs, using two major methods: externalizing the haptics through a clear corneal incision and tying a looped suture intraocularly using the cow hitch-knot technique $[7,8,10,13,14]$. These procedures do not require an incision for an IOL exchange, since the dislocated IOL is suture-fixated again [1-8, $13,14]$, which possibly reduces the risk of postoperative astigmatism or loss of corneal endothelium $[8,13,14]$.

Possible complications associated with transscleral fixation of foldable IOLs have also been discussed previously, i.e., IOL decentration, tilt, rotation or luxation, slippage of the suture thread off the haptic, and damage to the haptic [1, 6-11]. These complications are thought to result from the characteristic design and material of foldable IOL haptics, e.g., the absence of an eyelet or bulb to affix the suture, instability of the haptic-optic junction, and softness of the jelly-like material. The haptic of the single-piece acrylic IOL implanted in the current case was very soft, which may be the reason it was damaged.

The diameter of the IOL is additionally crucial to minimize stress on the single-piece acrylic IOL that is sutured. Based on published data, the diameter of the posterior chamber at the level of the ciliary sulcus can be estimated to range from about 10 to $12 \mathrm{~mm}$ [15]. In the current case, the largest diameter of the damaged IOL was $13 \mathrm{~mm}$, which seems sufficient to provide stability after suture fixation. However, the actual distance between the two suture sites was $10.5 \mathrm{~mm}$. If the distance between the two sutured parts was less than the diameter of the posterior chamber, the thin monofilament suture would induce continuous force across the haptic and gradually slice the jelly-like material of the haptic of a single-piece acrylic IOL. This hypothesis is supported by the tiny fissures on the relatively smooth surfaces of the cross-sections with the adherent suture thread.

While unpredictable complications can arise from inappropriate choices of a foldable IOL, foldable IOLs are advantageous even in suture fixation. Attention should be paid to the IOL design and material even during primary cataract surgery, and the possible complications of suturing those IOLs should also be considered; the complications may occur later, as there would be no chance to exchange the IOL during repositioning surgery with transscleral fixation. In addition, surgeons performing an IOL repositioning procedure should evaluate the design and material of the previously implanted IOL, and plan to exchange the IOLs when needed. Development of foldable IOLs suitable for both primary cataract surgery and transscleral fixation should solve this problem [12].

\section{Disclosure Statement}

The authors have no conflicts of interest to disclose. 
Tanaka et al.: Haptic Breakage after Transscleral Fixation of a Single-Piece Acrylic Intraocular Lens

\section{References}

1 Packer M, Fine IH, Hoffman RS: Suture fixation of a foldable acrylic intraocular lens for ectopia lentis. J Cataract Refract Surg 2002;28:182-185.

-2 Oshima Y, Oida H, Emi K: Transscleral fixation of acrylic intraocular lenses in the absence of capsular support through 3.5 mm self-sealing incisions. J Cataract Refract Surg 1998;24:1223-1229.

-3 Kaynak S, Ozbek Z, Pasa E, Oner FH, Cingil G: Transscleral fixation of foldable intraocular lenses. J Cataract Refract Surg 2004;30:854-857.

4 Ahn JK, Yu HG, Chung H, Wee WR, Lee JH: Transscleral fixation of a foldable intraocular lens in aphakic vitrectomized eyes. J Cataract Refract Surg 2003;29:2390-2396.

5 Choi KS, Park SY, Sun HJ: Transscleral fixation by injector implantation of a foldable intraocular lens. Ophthalmic Surg Lasers Imaging 2010;41:272-275.

6 Ma DJ, Choi HJ, Kim MK, Wee WR: Clinical comparison of ciliary sulcus and pars plana locations for posterior chamber intraocular lens transscleral fixation. J Cataract Refract Surg 2011;37:1439-1446.

-7 Sarrafizadeh R, Ruby AJ, Hassan TS, Williams GA, Garretson BR, Trese MT, et al: A comparison of visual results and complications in eyes with posterior chamber intraocular lens dislocation treated with pars plana vitrectomy and lens repositioning or lens exchange. Ophthalmology 2001;108:82-89.

$>8$ Chan CC, Crandall AS, Ahmed II: Ab externo scleral suture loop fixation for posterior chamber intraocular lens decentration: clinical results. J Cataract Refract Surg 2006;32:121-128.

-9 Bading G, Hillenkamp J, Sachs HG, Gabel VP, Framme C: Long-term safety and functional outcome of combined pars plana vitrectomy and scleral-fixated sutured posterior chamber lens implantation. Am J Ophthalmol 2007;144:371-377.

10 Nikeghbali A, Falavarjani KG: Modified transscleral fixation technique for refixation of dislocated intraocular lenses. J Cataract Refract Surg 2008;34:743-748.

11 McGrath LA, Lee GA: Transscleral fixation of a supplementary toric intraocular lens to prevent rotation in a pseudophakic patient. J Cataract Refract Surg 2013;39:134-138.

-12 Yaguchi S, Yaguchi S, Noda Y, Taguchi Y, Negishi K, Tsubota K: Foldable acrylic intraocular lens with distended haptics for transscleral fixation. J Cataract Refract Surg 2009;35:2047-2050.

13 Hanemoto T, Ideta H, Kawasaki T: Luxated intraocular lens fixation using intravitreal cow hitch (girth) knot. Ophthalmology 2002;109:1118-1122.

-14 Kokame GT, Yamamoto I, Mandel H: Scleral fixation of dislocated posterior chamber intraocular lenses: Temporary haptic externalization through a clear corneal incision. J Cataract Refract Surg 2004;30:10491056.

15 Kim KH, Shin HH, Kim HM, Song JS: Correlation between ciliary sulcus diameter measured by $35 \mathrm{MHz}$ ultrasound biomicroscopy and other ocular measurements. J Cataract Refract Surg 2008;34:632-637.

H.T. and K.F. contributed equally to this work and should be considered equivalent authors. 


\section{Case Reports in \\ Ophthalmology}

\begin{tabular}{l|l}
\hline \multicolumn{2}{l}{ Case Rep Ophthalmol 2014;5:212-216 } \\
\hline DOI: 10.1159/000365350 & $\begin{array}{l}\text { ○ 2014 S. Karger AG, Basel } \\
\text { www.karger.com/cop }\end{array}$ \\
\hline
\end{tabular}

Tanaka et al.: Haptic Breakage after Transscleral Fixation of a Single-Piece Acrylic Intraocular Lens
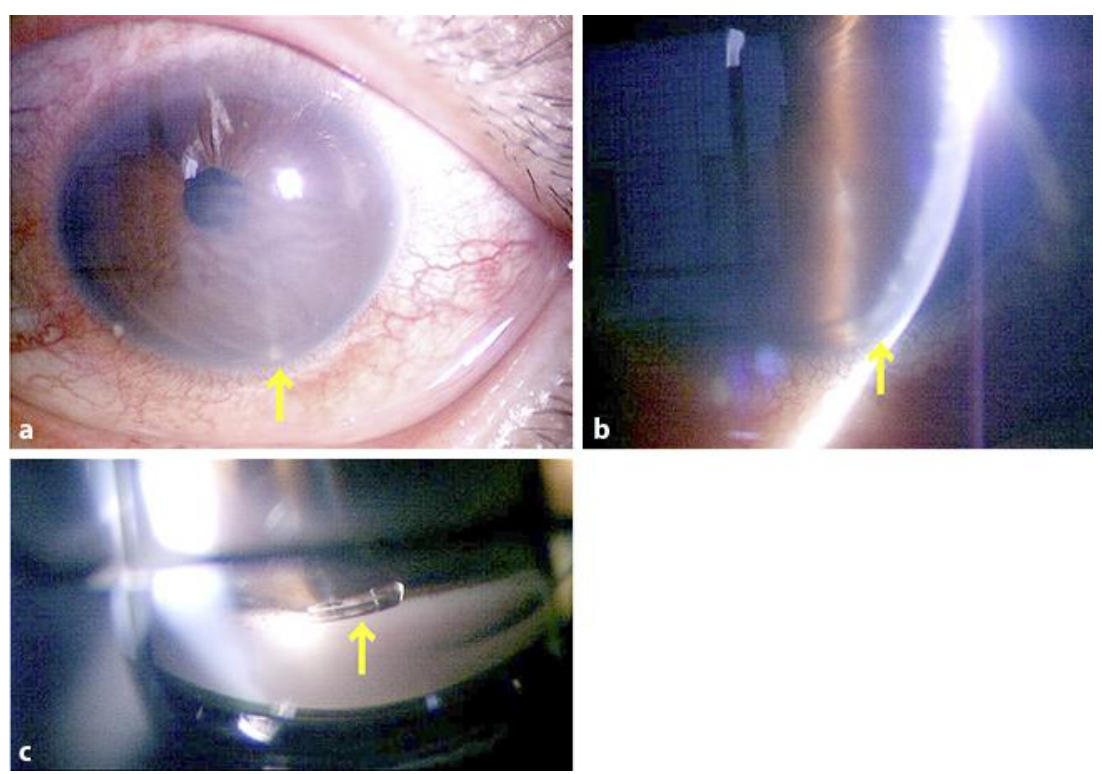

Fig. 1. Anterior segment findings at the initial examination. a, b Slit-lamp examination shows a foreign body (arrow) through the prominent corneal stromal edema from 2 to 7 o'clock in the LE. Lineal depigmentation is observed at 12 o'clock in the iris. c The foreign body (arrow) observed by gonioscopy is thought to be a tip of a single-piece acrylic IOL.

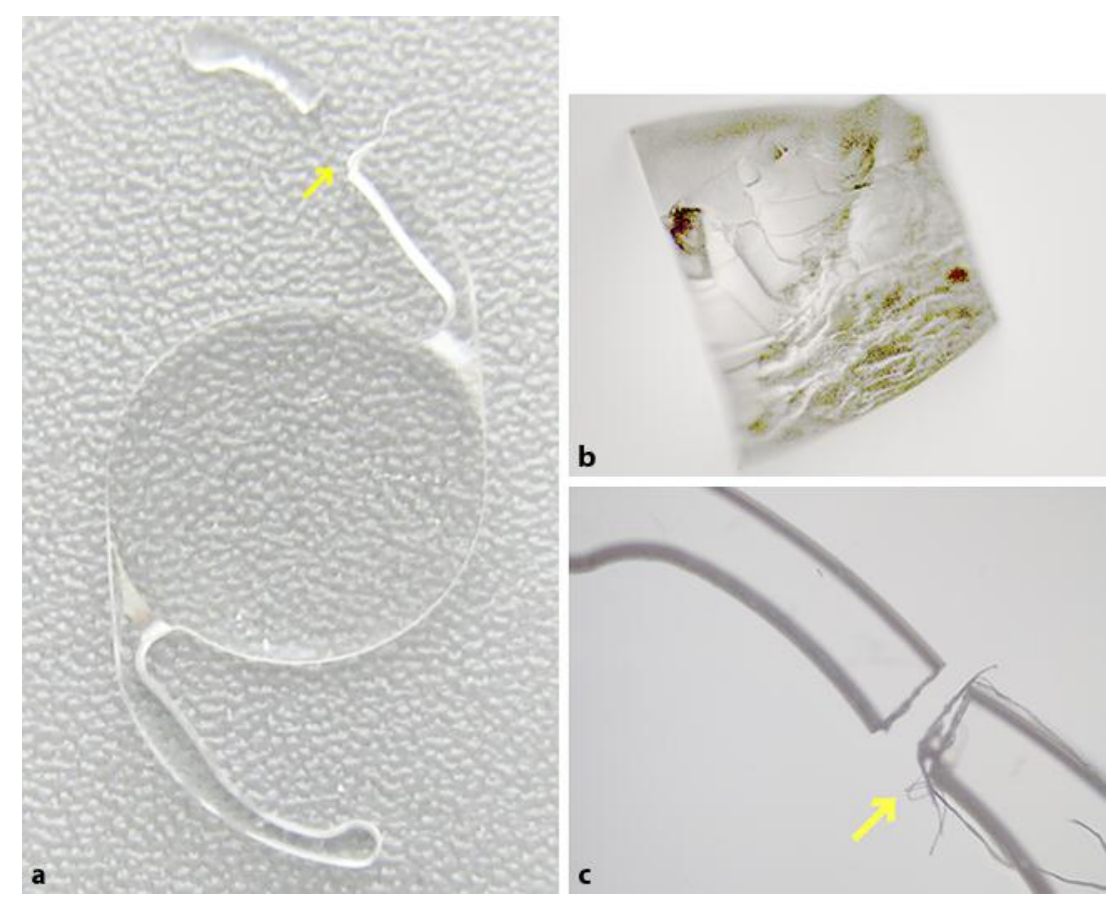

Fig. 2. Microscopic observations of the extracted IOL (AcrySof SA60AT). a The damaged site (arrow) is slightly proximal to the optic compared to the opposite sutured point, resulting in failure to be fixated at the greatest diameter of the IOL. $\mathbf{b}$ The surface of the severed portion is relatively flat and smooth. Numerous tiny fissures are seen, which developed due to the continuous force of the suture thread. c A monofilament suture thread (arrow) adheres to the proximal aspect of the severed haptic. 